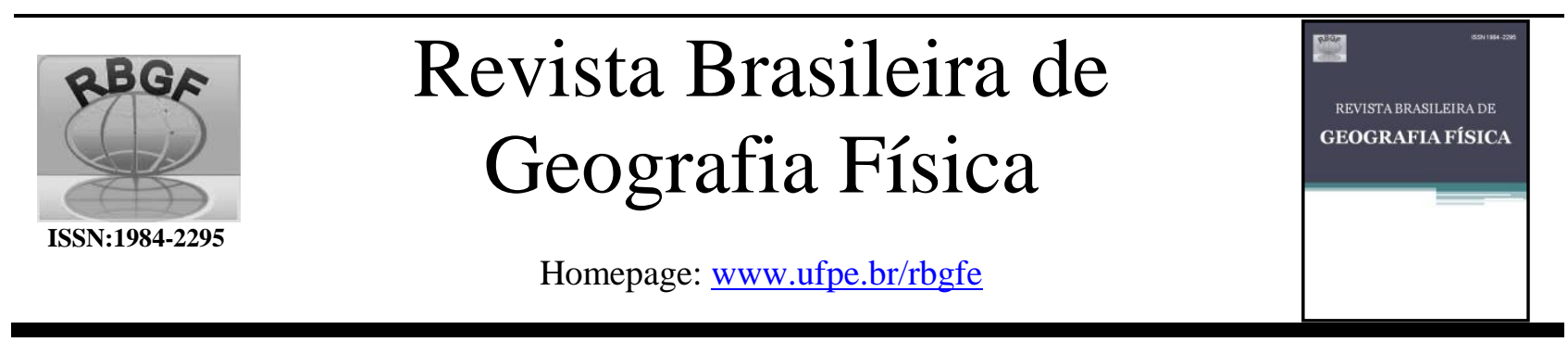

\title{
Reconstituição Paleoambiental da Área Arqueológica de Serra Negra, Face Leste do Espinhaço Meridional (Minas Gerais), através da Análise de Fitólitos
}

Karina Ferreira Chueng ${ }^{1}$, Heloisa Helena Gomes Coe $^{2}$, Marcelo Fagundes ${ }^{3}$, Alessandra Mendes Carvalho Vasconcelos ${ }^{4}$, Sarah Domingues Fricks Ricardo ${ }^{5}$

${ }^{1}$ Mestre e Doutoranda em Dinâmica dos Oceanos e da Terra, Universidade Federal Fluminense, Niterói, RJ. karinachueng@yahoo.com.br (autor
correspondente). ${ }^{2}$ Doutora em Geologia e Geofísica Marinha, Professora Adjunta, Faculdade de Formação de Professores da UERJ, São Gonçalo, RJ,
e Programa de Pós-graduação em Dinâmica dos Oceanos e da Terra, Universidade Federal Fluminense, Niterói, RJ. heloisacoe@ yahoo.com; ${ }^{3}$ Doutor
em Arqueologia, Professor Adjunto da Faculdade Interdisciplinar em Humanidades da Universidade Federal dos Vales do Jequitinhonha e Mucuri,
Diamantina, MG. marcelofagundes.arqueologia@ gmail.com; ${ }^{4}$ Doutora em Geografia e Análise Ambiental, Professora Adjunta nos cursos de
Engenharia Geológica e Bacharelado em Ciência e Tecnologia da Universidade Federal dos Vales do Jequitinhonha e Mucuri, Diamantina, MG.
alessandra.carvalho@ict.ufvjm.edu.br; ${ }^{5}$ Mestranda em Botânica, Museu Nacional, Universidade Federal do Rio de Janeiro. sarah.fricks@gmail.com. alessandra.carvalho@ict.ufvjm.edu.br; ${ }^{5}$ Mestranda em Botânica, Museu Nacional, Universidade Federal do Riod
Artigo recebido em 10/04/2018 e aceito em 28/08/2018

\section{R E S U M O}

A Serra do Espinhaço Meridional (SdEM) tem sido intensamente pesquisada por arqueólogos, produzindo um conhecimento significativo sobre a história indígena regional. Entretanto, também é necessário conhecer as condições paleoclimáticas e o contexto ambiental em que essas ocupações ocorreram. Este trabalho pretende contribuir com pesquisas já desenvolvidas pelo Laboratório de Arqueologia e Estudo da Paisagem da UFVJM na Área Arqueológica de Serra Negra, na face leste da SdEM, entre as bacias dos rios Jequitinhonha e Doce. O objetivo deste trabalho é a reconstituição paleoambiental desta região utilizando como indicadores os fitólitos, partículas de sílica que se depositam no interior das células das plantas e que permitem inferir a vegetação de onde se originaram. Em Felício dos Santos, foram coletados sedimentos do Sítio Arqueológico Cabeças 4, que foi ocupado em uma faixa cronológica entre 7225 anos AP e 480 anos cal AP. Além disso, coletou-se uma amostra em cada horizonte de um perfil de Organossolo próximo ao Sítio Arqueológico. Nas amostras do Sítio Arqueológico Cabeças 4 predominam fitólitos de gramíneas e palmeiras. Estes resultados foram corroborados com os do perfil de solo, que se apresentam preservados e distribuídos de forma homogênea. As análises de fitólitos se mostraram promissoras para inferências de variações climáticas e um maior conhecimento do ambiente em que se processou a ocupação arqueológica regional.

Palavras-chave: sítio arqueológico; organossolo; variações climáticas.

\section{Paleoenvironmental Reconstruction of the Archaeological Area of Serra Negra, East Face of the Southern Espinhaço (Minas Gerais), through Phytolith Analysis}

\begin{abstract}
A B S T R A C T
The Southern Espinhaço Mountain Range (SdEM) has been intensively studied by archaeologists, producing significant knowledge on the regional indigenous history. However, it is also necessary to know the paleoclimatic conditions and environmental context in which such occupations occurred. This work intends to contribute to research developed by the Archeology and Landscape Studies Laboratory of UFVJM in the Archaeological Area of Serra Negra, located on the eastern side of the SdEM, between the Jequitinhonha and Doce river basins. The objective of this work is paleoenvironmental reconstruction of this region using phytoliths, silica particles deposited inside plant cells, enabling inference of the vegetation from which they originated. Sediments were collected from the Cabeças 4 Archaeological Site, in Felício dos Santos, which was occupied during a chronological period between 7225 and 480 years cal BP. In addition, a sample was collected from each horizon of an organosol profile near the Archaeological Site. Phytoliths from grasses and palm trees predominate in the samples from the Cabeças 4 Archaeological Site. These results were corroborated with the types found in the soil profile, which are preserved and homogeneously distributed in the profile. Therefore, the phytolith analyses were promising for inferences of climatic variations and for improving knowledge on the environment in which the regional archaeological occupation occurred.
\end{abstract}

Keywords: archaeological site; organosol; climatic variations. 


\section{Introdução}

A Serra do Espinhaço Meridional (SdEM) está localizada entre três importantes bacias hidrográficas, dos rios São Francisco, Jequitinhonha e Doce. A disposição geomorfológica foi responsável pela constituição de diferentes ecossistemas, sendo a maior parte de seu território constituída pelo domínio fitoecológico do cerrado (Fagundes, 2013). Apesar de ter sido objeto de várias pesquisas interdisciplinares, pode-se afirmar que esse território ainda é arqueologicamente mal conhecido, uma vez que se calcula que menos de $10 \%$ do total de sua superfície foi prospectada. Tal fato, por sua vez, indica o altíssimo potencial arqueológico regional (Fagundes, 2016), que é objeto de pesquisa do Laboratório de Arqueologia e Estudo da Paisagem (LAEP) da Universidade Federal dos Vales do Jequitinhonha e Mucuri (UFVJM). O Laboratório desenvolve pesquisas no Alto Vale do Jequitinhonha e tem ainda, como demais objetivos, a verificação das condições paleoclimáticas e contexto ambiental em que as ocupações ocorreram, questões fundamentais para a compreensão arqueológica e para o repertório cultural da SdEM.

O objetivo deste trabalho é a reconstituição paleoambiental da Área Arqueológica da Serra Negra, na Borda Leste do Espinhaço Meridional, para compreensão do repertório cultural e ocupações pretéritas desta região. Como indicadores foram escolhidos os fitólitos, partículas microscópicas $(<60-100 \mu \mathrm{m})$ de opala biogênica, que se formam por precipitação de sílica amorfa entre e no interior de células de diversas plantas vivas, formadas como resultado da absorção de ácido silícico $[\mathrm{Si}(\mathrm{OH} 4)]$ da solução do solo pelas plantas (Coe et al., 2015). A célula vegetal onde o fitólito é formado funciona como um "molde" que vai determinar a forma dessas partículas. Por serem constituídos por sílica, os fitólitos se preservam bem em condições oxidantes, como os solos (Coe et al., 2017).

Os estudos fitolíticos, principalmente quando associados a outros indicadores (análise

\section{Área de Estudo}

A Serra do Espinhaço é um marco geográfico para Minas Gerais e sua relevância vai desde as feições da paisagem até os aspectos culturais da mesma. A região arqueológica de multiproxy), são úteis para a interpretação de condições paleobiogeoclimáticas (Yost et al., 2018; Neumann et al., 2017; Ball et al., 2016; Evett et al., 2016; Field et al., 2016; Hart, 2016; Hodson, 2016; Pearsall, 2016; Zurro et al., 2016; Albert et al., 2015; Vrydaghs et al., 2015; McCune et al., 2015; Power et al., 2014; Hyland et al., 2013; Watling et al. 2013). No Brasil, estudos recentes foram realizados por Coe et al. (2018), Babot et al. (2017), Calegari et al. (2017a, 2017b), Coe et al. (2017), Parolin et al. (2017), Santos (2017), Chueng (2016), Paisani et al. (2016), Silva et al. (2016), Santos et al. (2015), Luz et al. (2015), Calegari et al. (2015) Coe et al. (2015), Coe et al. (2014), Calegari et al. (2013), Coe et al. (2013). Na Serra do Espinhaço Meridional, pesquisas de Barros et al. (2016) e Augustin et al. (2014), utilizando fitólitos como indicadores de variações climáticas em áreas de formações de cerrado, se mostraram promissoras para os conhecimentos sobre a vegetação e clima desta região.

A análise de fitólitos tornou-se uma ferramenta arqueobotânica cada vez mais popular nas últimas décadas, principalmente para corroborar hipóteses relacionadas com a domesticação de várias culturas alimentares e ao estudo da dieta antiga, e são de particular importância em contextos onde outros restos de plantas são mal preservados. Numerosos estudos foram realizados com fitólitos extraídos de sedimentos arqueológicos e superfícies de artefatos (por exemplo Shillito, 2013; Ishida et al., 2003), mas a análise de fitólitos recuperados de solos arqueológicos é menos comum (Astudillo, 2018). Entretanto, não há muitos estudos visando a reconstituição das condições paleoambientais em sítios arqueológicos, sobretudo no Brasil, podendo ser citado o de Coe et al. (2017) no Sambaqui da Tarioba, Rio das Ostras, RJ, sendo, portanto, este trabalho um dos pioneiros. Acredita-se que os resultados das análises fitolíticas, associados à geocronologia e dados arqueológicos possam contribuir para a compreensão da evolução da paisagem natural e cultural da área de estudo.

Felício dos Santos está inserida no Planalto Diamantinense. A Área Arqueológica de Serra Negra, situada na borda leste do Espinhaço Meridional (Figura 1), tem sido pesquisada pela equipe da UFVJM, obtendo resultados significativos sobre as ocupações regionais (Fagundes, 2016). 


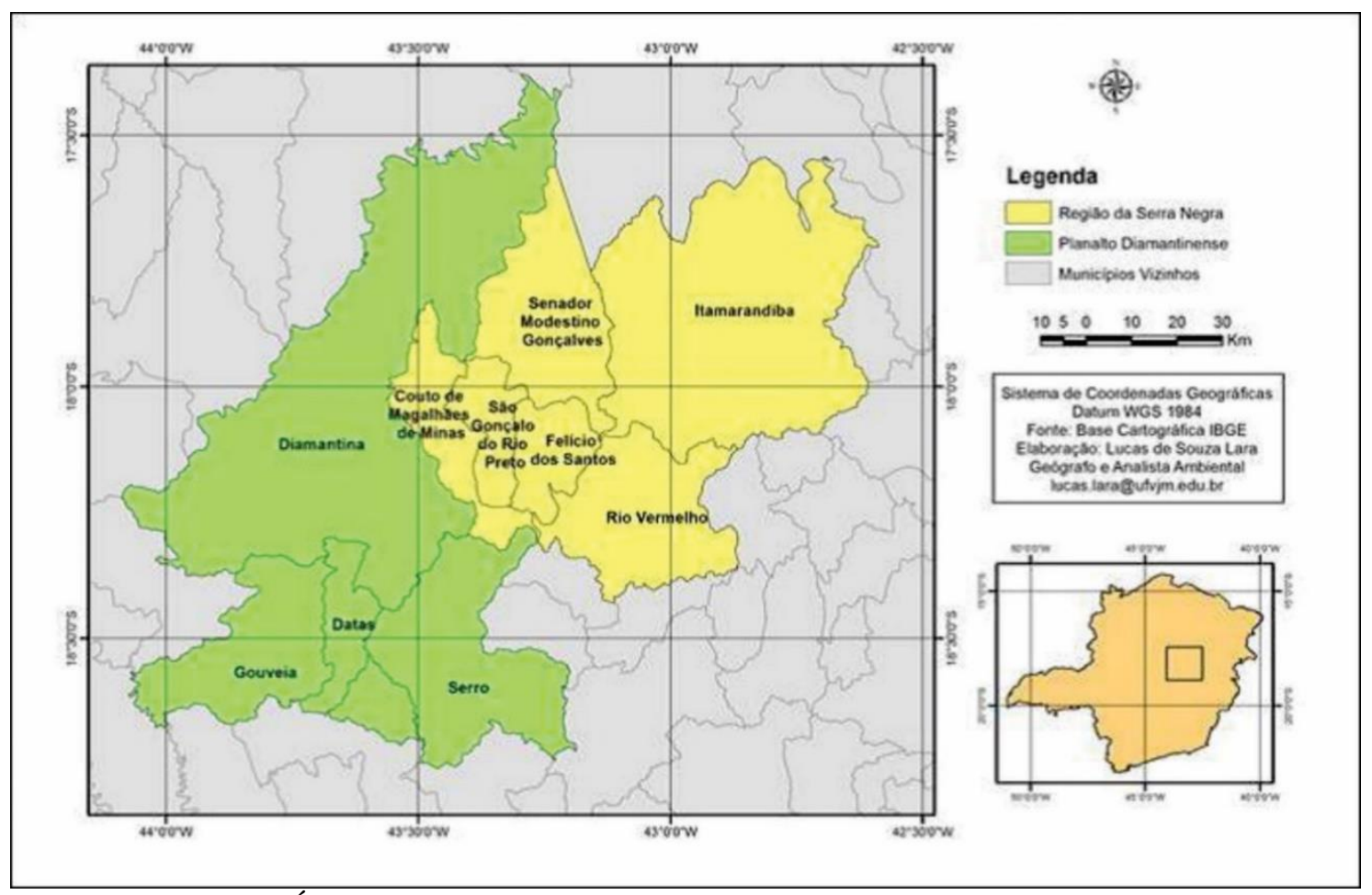

Figura 1: Mapa geral da Área Arqueológica de Serra Negra, com destaque para os principais municípios abrangidos pelas pesquisas (Fonte: Fagundes, 2016).

A área de estudo tem como principal unidade geológica o Supergrupo Espinhaço, com rochas como quartzitos, filitos e metaconglomerados em sua maioria. Os Sítios Cabeças, por sua vez, estão localizados em rochas da Formação Sopa-Brumadinho do Supergrupo Espinhaço. A geomorfologia regional é marcada por relevo íngreme, com afloramento rochoso e presenças de rampas de colúvio na região dos sítios arqueológicos. O Compartimento da Serra Negra está situado na porção nordeste da área de estudo englobando a Serra de mesmo nome. Nas altitudes mais elevadas, notavelmente nos topos da Serra, ocorre espessa camada de quartzito pertencente ao Grupo Guanhães (Fonseca et al., 2014).

No que tange à hidrografia, a área está inserida entre duas bacias hidrográficas importantes: do rio Doce, a leste; e do rio do Jequitinhonha, a oeste. Grande parte dos sítios está implantada na sub-bacia do rio Araçuaí (sobretudo os localizados em terras de Felício dos Santos), mas há sítios nas bacias dos rios Itanguá, do Itamarandiba (ambos componentes da bacia do rio Jequitinhonha) e Suaçuí-Grande, afluente do rio Doce (Fonseca et al., 2014).

No que se refere ao clima, o fator orográfico é de grande influência regional, sendo caracterizado como mesotérmico (Cwb na classificação de Geiger-Köppen), marcado por verões brandos e úmidos (outubro a abril), invernos mais frescos e secos (junho a agosto), com pequenas transições nos meses de maio e setembro. A precipitação varia de $1250 \mathrm{~mm}$ a $1550 \mathrm{~mm}$ e a temperatura média anual varia entre $18^{\circ}$ a $19^{\circ} \mathrm{C}$. A vegetação é caracterizada pela Floresta Estacional Semidecídua (Fonseca et al., 2014).

\section{O Sítio Cabeças 4 - Repertório Cultural e Cronologias}

O sítio Cabeças 4 está implantado em um amplo abrigo sob rocha quartzítica-micácea, como dito, em uma área de Floresta Estacional Semidecidual, no sopé da Chapada do Couto, área com grande concentração de sítios arqueológicos, todos abrigos com arte rupestre associada. $\mathrm{Na}$ verdade, trata-se de uma cavidade (abertura L-O), com comprimento de $13,56 \mathrm{~m}$ e profundidade $11,48 \mathrm{~m}$, altura média de $6,80 \mathrm{~m}$.

O sítio foi identificado por moradores locais, sobretudo em função de amplos painéis rupestres dispostos em suas paredes e tetos, com temática associada ao que foi definido para a tradição Planalto em Minas Gerais (Fagundes, 2016) (Figura 2). 

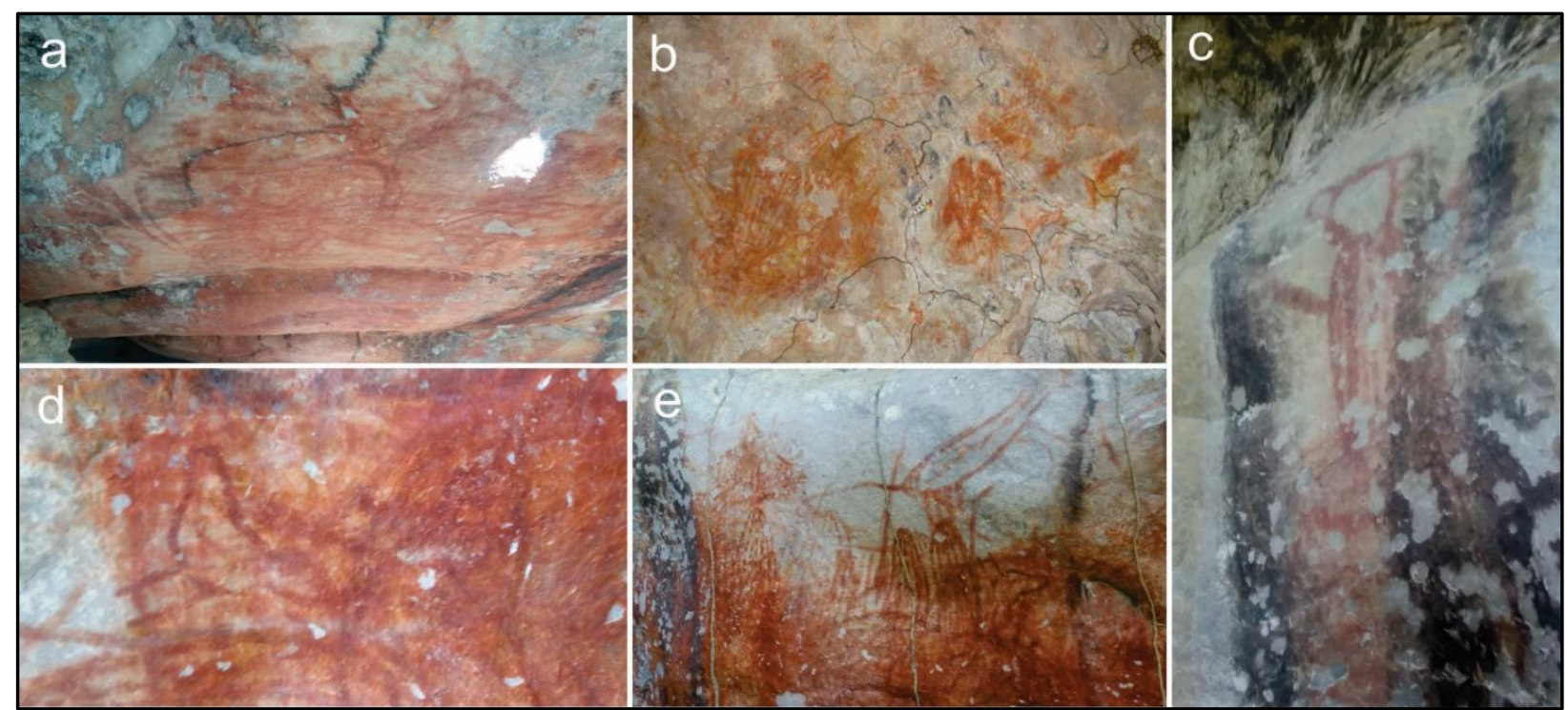

Figura 2: Painéis rupestres dos sítios a) Cabeças 02, destaque para zoomorfo (cervídeo); b) Cabeças 04, sobreposições de zoomorfos no teto do abrigo; c) Cabeças 01, zoomorfo; d) Cabeças 04, com destaque para sobreposições; e) Cabeças 01, com destaque para sobreposições e justaposições ente cervídeos e peixes (Fonte: acervo do LAEP, 2014 e Coe, 2016).

A superfície disponível para escavação é ampla, representada por piso plano, com presença de poucos blocos abatidos. Em sua frente, voltada para leste, há um grande paredão de vegetação, com dossel arbóreo que ultrapassa 4 metros de altura, conferindo proteção aos painéis, porém baixa luminosidade, sobretudo no período da tarde. Além disso, toda a área é protegida de chuvas, inclusive as mais fortes, de modo que seu piso atual permaneça intacto às ações de enxurradas. Da área total do sítio (Figura 3), foram selecionados apenas $3 \mathrm{~m} 2$ para intervenção (levando em conta a metodologia estabelecida para escavações regionais), subdivididos em três quadrículas nomeadas de D30 (face oeste), E30 (central) e F30 (face leste). Contrariando as expectativas de um pacote sedimentar curto para a Serra do Espinhaço Meridional, foi possível alcançar uma maior profundidade do que nas demais escavações, entre 58/62 cm (Isnardis, 2013, Fagundes, 2013).

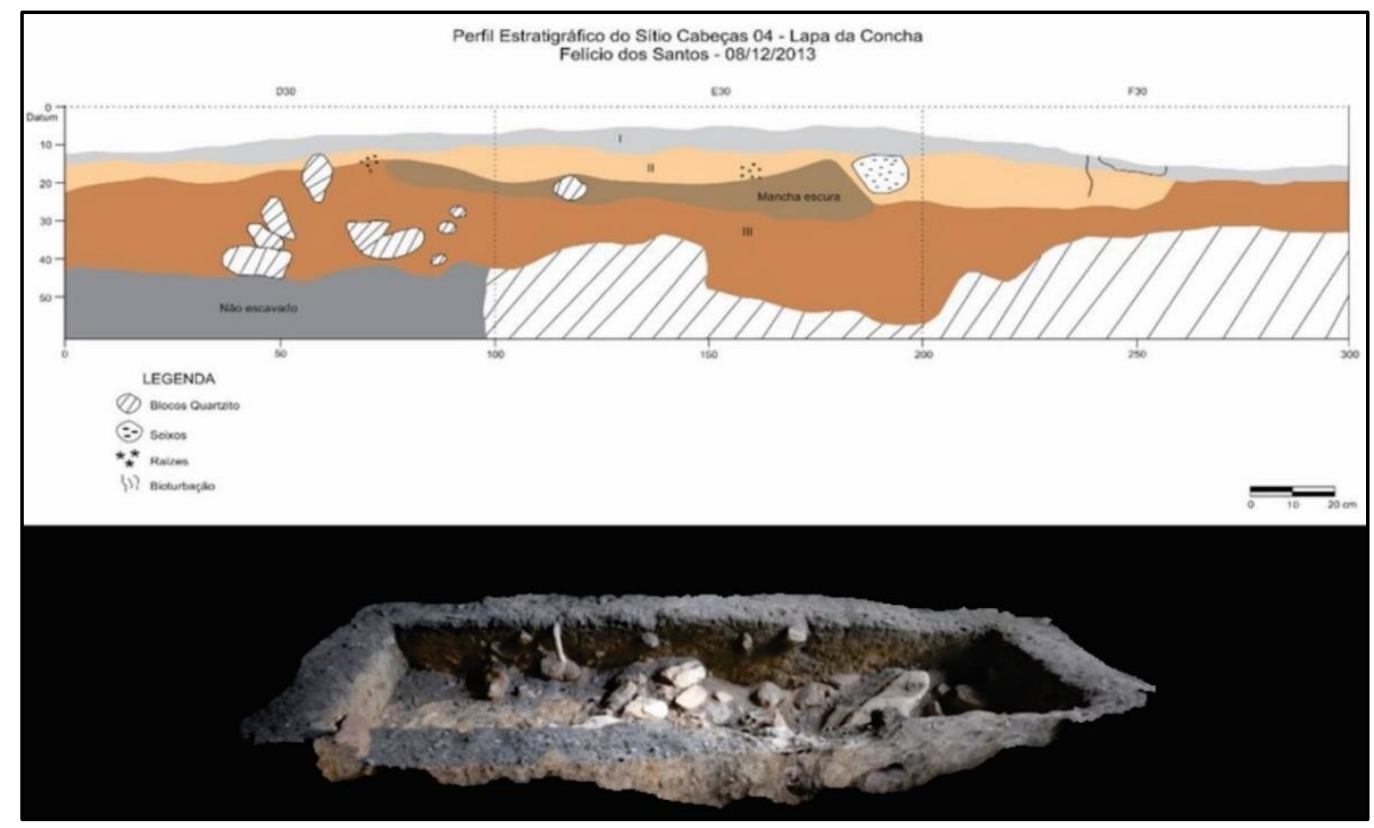

Chueng, K. F., Coe, H. H. G., Fagundes, M., Vasconcelos, A. M. C., Ricardo, S. D. F. 
Figura 3: Perfil estratigráfico do sítio Cabeças 04 (Fonte: acervo do LAEP, 2015)

Ao fim da escavação foi possível identificar três camadas com distintos pacotes ocupacionais, a saber (Figura 4):

(a) Camada I (com um pacote de ocupação não datado) - representada por sedimento menos compacto, bem arenoso, com presença de poucos vestígios líticos e cerâmicos, associados a grupos de horticultores. A espessura média desta camada é de $4 / 5 \mathrm{~cm}$ (com base na estratigrafia da quadrícula E30);

(b) Camada II (com um pacote de ocupação) o sedimento adquire uma tonalidade marrom clara, mais compactado, com presença de algumas estruturas de combustão, sendo datação média de $480 \pm 30$ anos AP. Além dos vestígios líticos (lascados e polidos, este último representado por uma lâmina de machado completa) foram evidenciados 14 fragmentos pequenos de cerâmica, material faunístico e botânico (em análise), também associados às ocupações horticultoras. A espessura média desta camada é de $14 / 15 \mathrm{~cm}$ (com base na estratigrafia da quadrícula E30);

(c) Camada III (com três pacotes de ocupação) - bem mais compactada, de tonalidade marrom avermelhado (silto-arenosa, inicia-se com tonalidade alaranjada), com presença de blocos de quartzito associados, além de seixos. Trata-se da camada associada ao Holoceno Médio, com três distintos momentos de ocupação entre 7225 e 4000 anos AP. O repertório cultural está marcado por uma diversificada indústria lítica, sobretudo em quartzo (Fagundes, 2016) (Figura 5). A espessura média da camada é de $35 / 37 \mathrm{~cm}$, com base na estratigrafia da quadrícula E30.

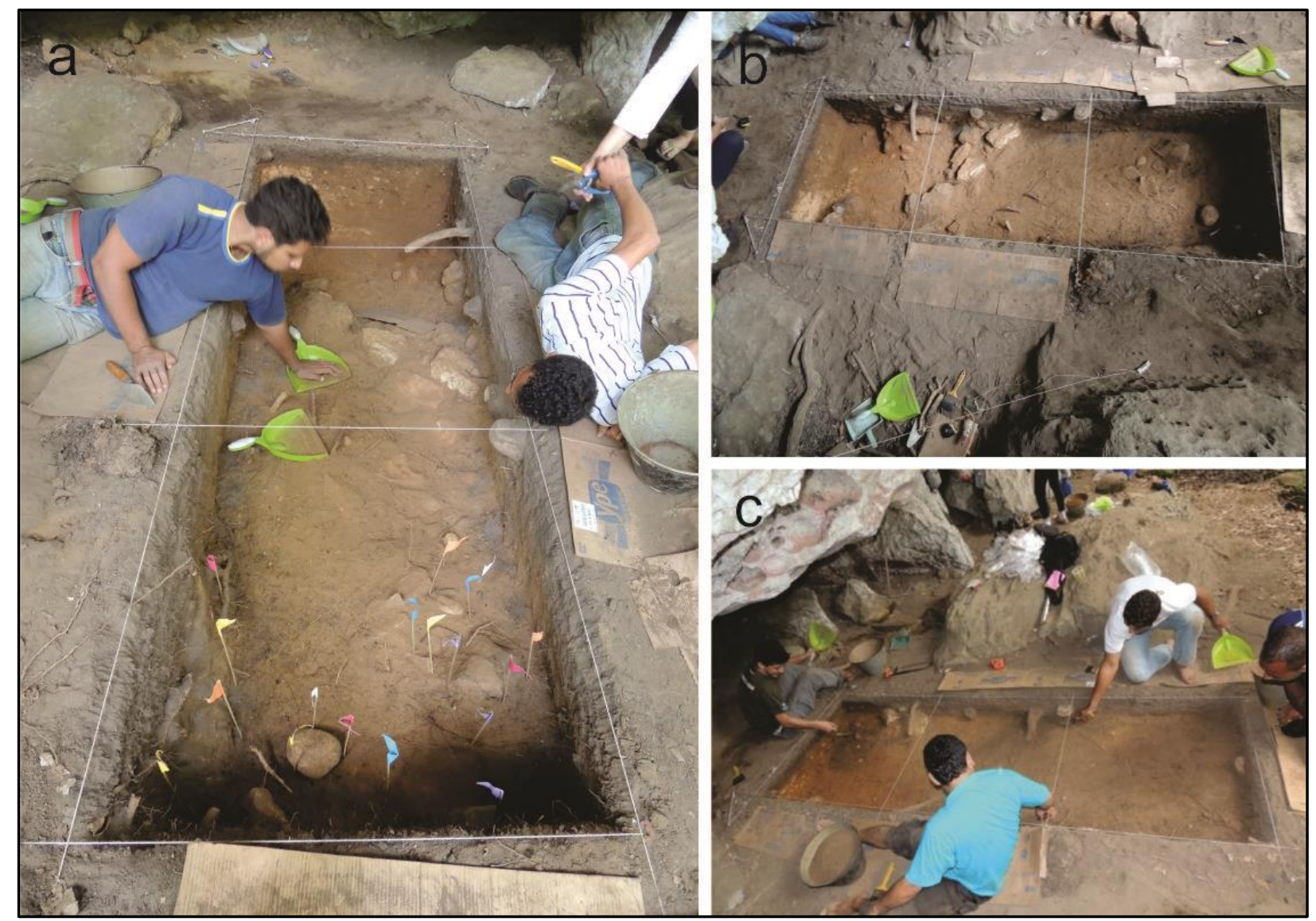

Figura 4: Visão geral da área de escavação: a) Escavação do pacote associado ao Holoceno Médio, destaque para evidenciação e recolhimento de vestígios; b) Vista superior da área de escavação, também do pacote associado ao Holoceno Médio; c) Evidenciação de estrutura de combustão, canto esquerdo, datada em $4010 \pm 40$ anos cal AP (Fonte: acervo do LAEP, 2014) 

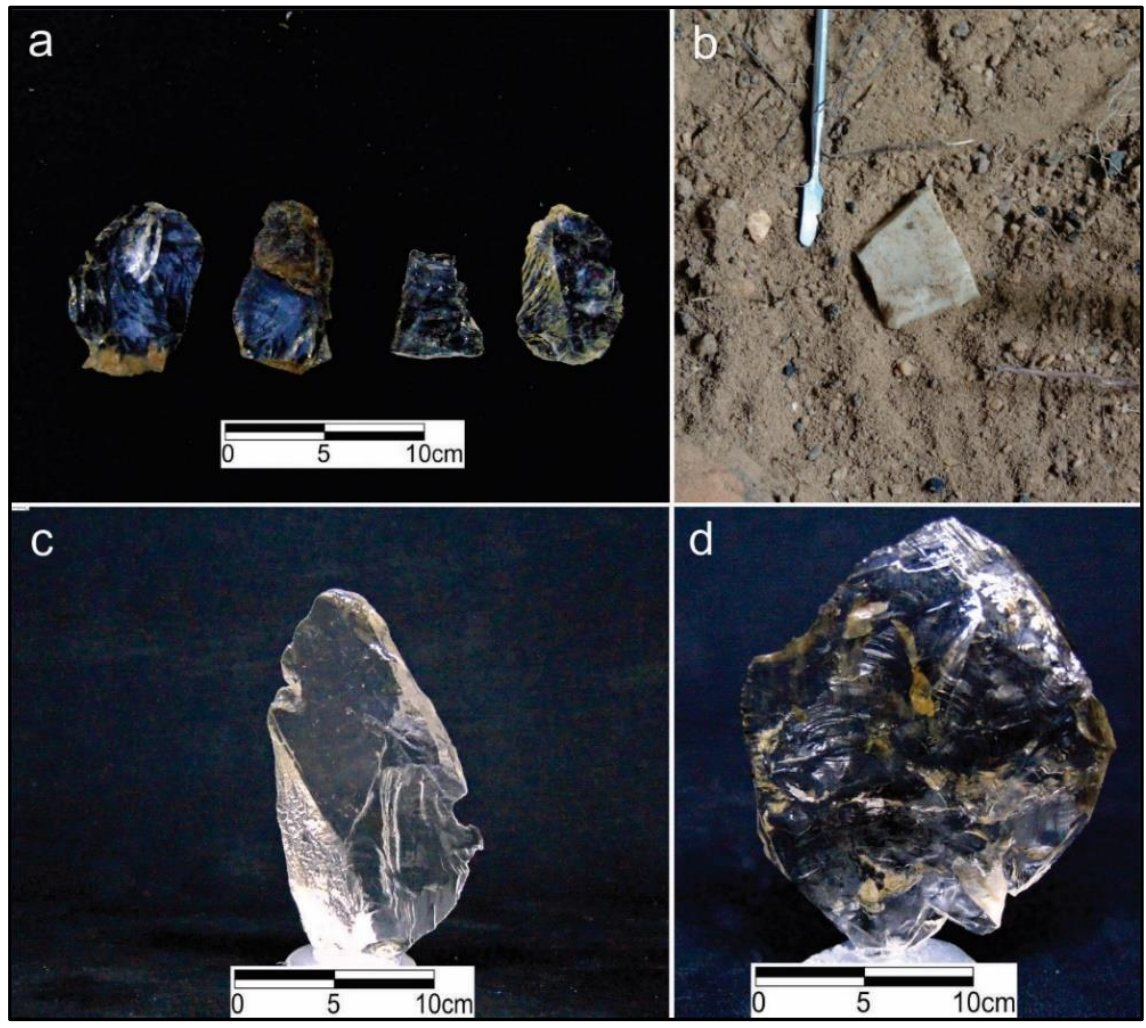

Figura 5: Material lítico observado no Sítio Cabeças 4: a) Lascas de façonagem em quartzo hialino; b) Mesial de artefato plano convexo sobre plaqueta de quartzito; c) Lasca bruta de debitagem em quartzo hialino; d) Artefato sobre lasca em quartzo hialino (Fonte: acervo do LAEP, 2014).

Contrariando as teorias acerca do Hiato do Arcaico, o sítio Cabeças 4 apresentou datações a partir do Holoceno Médio, período onde ocorreram três ocupações distintas associadas a grupos de caçadores coletores, a partir do nível 11/12 até o final da escavação (Tabela 1):

(a) Primeira ocupação: entre 7255-7170anos cal AP e 7160 a 7100 anos cal AP, marcada pela presença de uma indústria lítica em quartzo hialino, com predominância da técnica unipolar de lascamento. De acordo com Fagundes (2016), apesar da existência de lascas bipolares, a presença da técnica unipolar para obtenção de suportes é o grande destaque da indústria, que parece ser uma marca regional, presente no conjunto artefatual do sítio Sampaio, por exemplo, também um abrigo com datação do Holoceno Médio, com cronologia de $4280 \pm 30$ (Fagundes et al., 2017) (Figura 5);

(b) Segunda ocupação: por volta de 6180 a 6150 anos cal AP, também marcada pela presença majoritária de lascas de quartzo hialino obtidas pela técnica unipolar. Destaque para a presença, mesmo que muito sutil, de vestígios em quartzito, inclusive com a evidenciação de um mesial de plano convexo (Figura 5b);

(c) Terceira ocupação: entre 4520-4420 a 44454420 anos cal AP, onde há uma continuidade do que foi visto na segunda ocupação no que tange à indústria lítica (Figura 5).

Tabela 1: Datações associadas a grupos de caçadores-coletores do sítio Cabeças 04 (Fonte: Fagundes, 2016)

\begin{tabular}{ccccc}
\hline Ocupação & Camada & $\begin{array}{c}\text { Laboratório / } \\
\text { Identificação }\end{array}$ & Idade $^{14} \mathbf{C}$ & $\begin{array}{c}\text { Idade Calibrada } \\
\text { (anos cal AP) }\end{array}$ \\
\hline Ocupação 01 & III & BETA 379290 & $6290 \pm 30$ & 7255 a 7170 \\
Ocupação 01 & III & BETA 379290 & $6140 \pm 40$ & 7160 a 7100 \\
Ocupação 02 & III & BETA 370289 & $5270 \pm 40$ & 6180 a 6150 \\
Ocupação 02 & III & BETA 370291 & $4010 \pm 40$ & 4520 a 4420
\end{tabular}

Chueng, K. F., Coe, H. H. G., Fagundes, M., Vasconcelos, A. M. C., Ricardo, S. D. F. 
Assim, de modo geral, para a indústria lítica apesar do baixo índice de artefatos acabados, Fagundes et al. (2017) destacam que esta indústria em quartzo do Holoceno Médio é marcada pela presença de estigmas de lascamento que indicam a produção de artefatos sofisticados (dada à grande concentração de lascas de façonagem e retoques). A marca principal é o lascamento unipolar que, de acordo com Fagundes (2016), deve estar relacionado aos processos de obtenção e apropriação da matéria-prima localmente disponível, representada por grandes blocos de cristal anédrico. Neste sentido, Fagundes et al. (2017) apontam para uma mudança na organização tecnológica dos grupos que ocuparam Serra Negra, sobretudo quando seus conjuntos são comparados ao que fora estudado em outras áreas do Espinhaço
Meridional por Isnardis (2013) no Planalto Diamantinense e na Serra do Cipó.

Portanto, destaca-se a importância do Cabeças 04 (e de outros assentamentos regionais) no que tange às discussões acerca das ocupações do Holoceno no Planalto Central brasileiro, além de outras temáticas relacionadas à arte rupestre e os conjuntos líticos, todas com muito destaque na literatura nacional.

\section{Materiais e Métodos}

Em Felício dos Santos, foram coletados sedimentos do Sítio Arqueológico Cabeças 4 (coordenadas: $18^{\circ} 22,1^{\prime} 06^{\prime} ' \mathrm{~S} \quad 43^{\circ} 24,6^{\prime} 12^{\prime}{ }^{\prime} \mathrm{O}$; altitude: $1002 \mathrm{~m}$ ). Os sedimentos foram coletados em intervalos de $5 \mathrm{em} 5 \mathrm{~cm}(0-45 \mathrm{~cm})$ para análise de fitólitos (Figura 6).

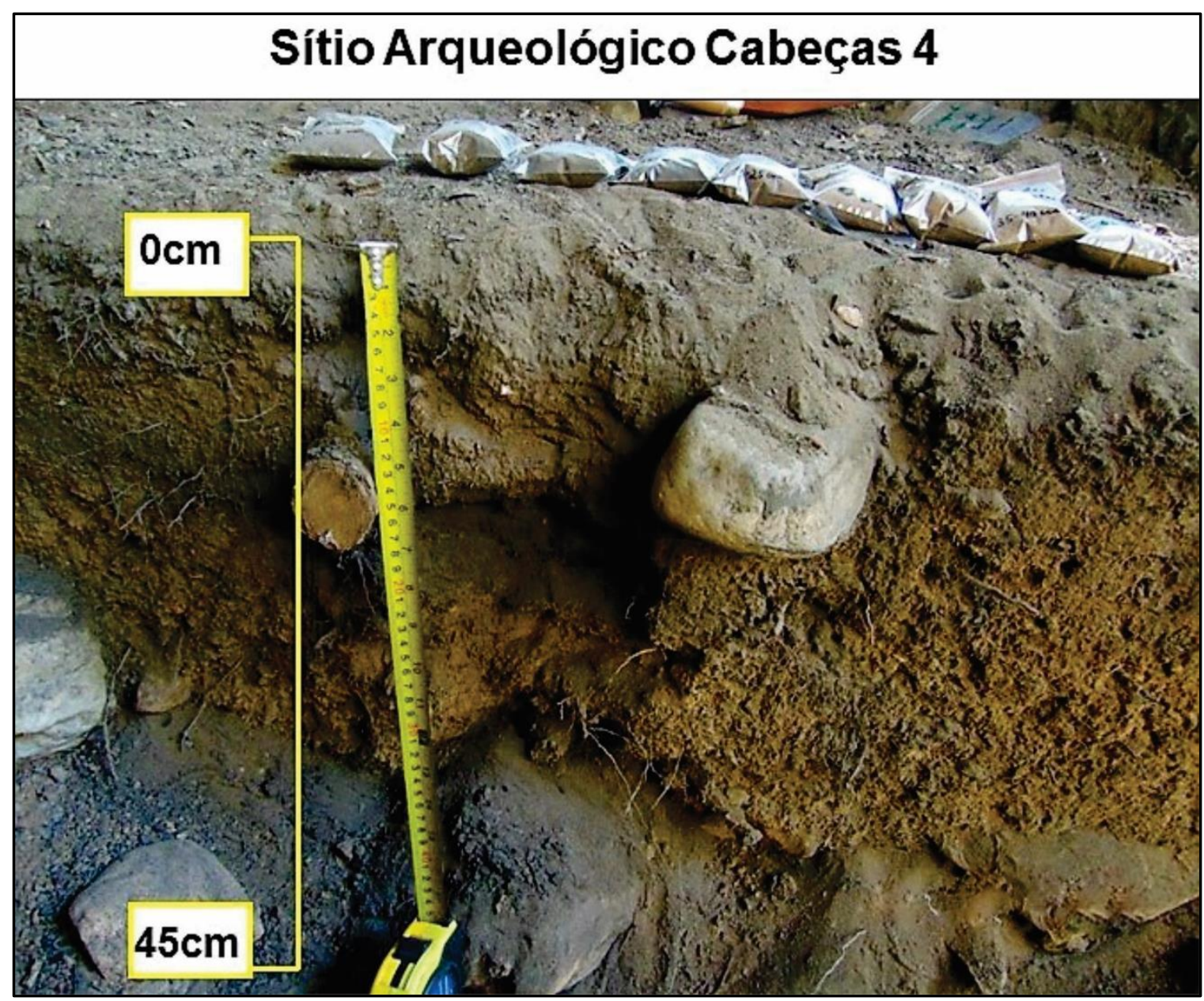

Figura 6: Amostras de sedimentos coletadas no Sítio Arqueológico (Foto Chueng, 2016)

Chueng, K. F., Coe, H. H. G., Fagundes, M., Vasconcelos, A. M. C., Ricardo, S. D. F. 
Além disso, coletou-se uma amostra em cada horizonte de um perfil de Organossolo (Horizonte A: 0-15cm; Horizonte Orgânico 1: 15$88 \mathrm{~cm}$; Horizonte Orgânico 2: $88-175 \mathrm{~cm}$ ) situado próximo ao sítio arqueológico (coordenadas: $18^{\circ} 21,2^{\prime} 09^{\prime}$ 'S/ 4325,4'15,2'O; altitude: 995m) (Figura 7).

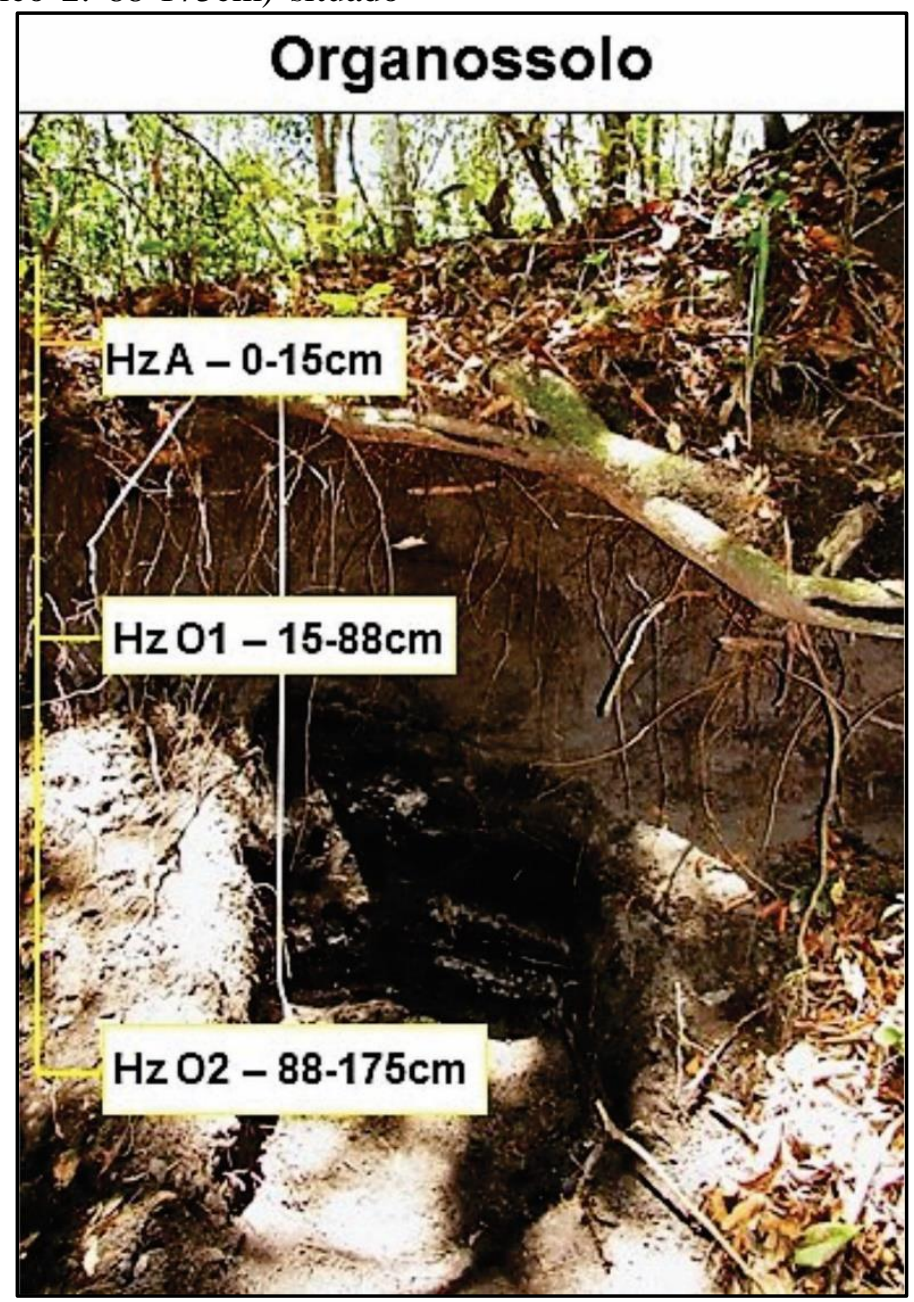

Figura 7: Amostras coletadas no perfil de Organossolo (Foto Chueng, 2016)

A extração de fitólitos dos sedimentos do Sítio Arqueológico e do perfil de solo foram realizadas nos laboratórios do LAGEMAR/UFF, seguindo o Protocolo de Extração de Fitólitos de Sedimentos e Solos adaptado daquele utilizado pela equipe do Prof. Dr. Mauro Parolin, da Faculdade Estadual de Ciências e Letras de Campo Mourão (FECILCAM), Paraná. A preparação inicial consistiu em secar e peneirar a $2 \mathrm{~mm} 10 \mathrm{~g}$ de amostra e eliminar carbonatos (com $\mathrm{HCl}$ ), óxidos de ferro (com Citrato e Diotinito de Sódio), a matéria orgânica (com ácido nítrico, ácido sulfúrico e $\mathrm{H}_{2} \mathrm{O}_{2}$ ) e a fração argila (por decantação). Tomou-se uma alíquota de $25 \mu \mathrm{l}$ do material (precipitado) e confeccionam-se lâminas para microscopia em óleo de imersão (temporárias) e Entellan ${ }^{\circledR}$ (permanentes), nas quais foi realizada a determinação de seu conteúdo, a descrição dos principais morfotipos de fitólitos e estado de alteração das partículas.

A microscopia foi realizada no Laboratório de Microscopia Óptica e Morfoscopia (LAMOM) da Faculdade de Formação de Professores da UERJ. Foram feitas a identificação e contagem ao microscópio óptico, com aumento de 500 a 630 x, de pelo menos 200 fitólitos classificáveis a fim de: a) estimar a frequência relativa dos distintos morfotipos segundo o Código Internacional de Nomenclatura de Fitólitos (ICPN); b) analisar o grau de alteração dos fitólitos (classificáveis / não classificáveis); c) calcular o estoque total de fitólitos em cada amostra. A partir desta contagem, calculam-se índices fitolíticos (relações de abundância de determinados morfotipos de fitólitos), que permitem inferir parâmetros de vegetação, tais como: (1) a densidade da cobertura 
arbórea (D/P), (2) a densidade de palmeiras (Pa/P), (3) o índice de aridez (Iph), (4) o índice climático (Ic) e (5) o índice de estresse hídrico (Bi) (Coe et al., 2013).

\section{Resultados e Discussão}

Foram observados fitólitos em todas as amostras, tanto do Sítio Arqueológico (S.A) quanto do perfil de solo (P.S), sendo que o organossolo apresentou maior quantidade (de 382 a 527 em 3 transectos horizontais) que o sítio arqueológico (de 284 a 319). Em ambos, os estoques de fitólitos seguem o padrão normal de diminuição com a profundidade (Tabela 2 e Figura 8).

Os fitólitos se encontram muito bem preservados, tanto no Sítio Arqueológico (de 75 a $82 \%$ de fitólitos classificáveis), quanto no Organossolo (de 83 a 87\%). No Organossolo, o percentual de fitólitos classificáveis segue o padrão normal de diminuição do estado de conservação com a profundidade (Tabela 2 e Figura 8B). Já no Sítio Arqueológico não existe esse padrão, provavelmente por ter sofrido intervenção antrópica, porém em ambos os pontos de coleta a preservação é bastante homogênea.

As amostras do Sítio Arqueológico Cabeças 4 (Tabela 2 e figuras $8 \mathrm{~A} \mathrm{e} 9$ ) apresentaram predominância de fitólitos de gramíneas (entre 58 e 70\%), principalmente dos tipos de Poaceae de regiões temperadas ou tropicais de altitude, como rondel (8 a 18\%) e trapeziform (de 4 a $7 \%$ ), de Poaceae de ambientes úmidos como bilobate (de 6 a 17\%) e cross (de 3 a 10\%), porém com estresse hídrico, já que o tipo bulliform representa de 17 a 19\% dos fitólitos classificáveis. Além desses tipos, foram observados fitólitos produzidos por Arecaceae, o tipo globular echinate (de 13 a 18\%) e por dicotiledôneas lenhosas, o tipo globular granulate (de 8 a 13\%), além de uma considerável quantidade do tipo elongate (de 9 a 16\%), produzido principalmente por Poaceae mas que também pode ser observado em dicotiledôneas lenhosas.

Esses resultados foram corroborados com os tipos encontrados no Perfil de Organossolo, semelhantes aos do Sítio Arqueológico (Tabela 2 e figuras $8 \mathrm{~B}$ e 9 ).

Tabela 2: Principais morfotipos de fitólitos observados no Perfil de Solo (em \% de fitólitos classificáveis)

\begin{tabular}{|c|c|c|c|c|c|c|c|c|c|c|c|c|c|c|c|c|c|c|}
\hline 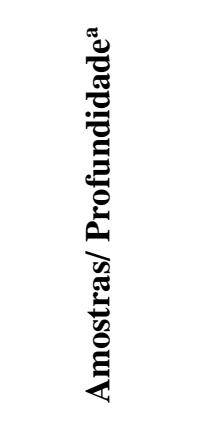 & 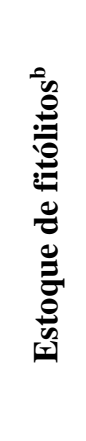 & 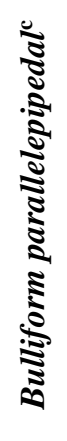 & 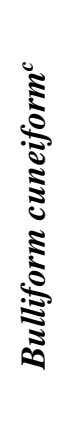 & 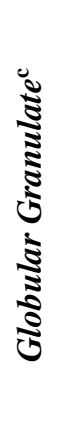 & 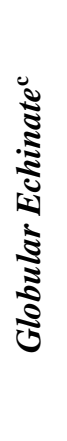 & 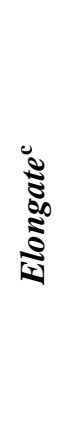 & 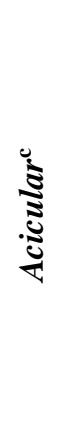 & 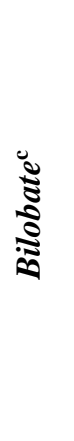 & $\begin{array}{l}\tilde{y} \\
\stackrel{u}{0}\end{array}$ & 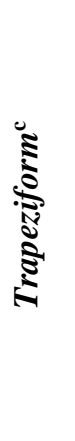 & 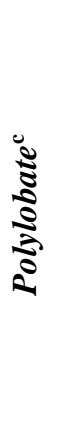 & 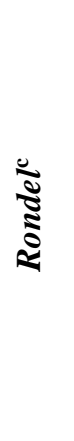 & 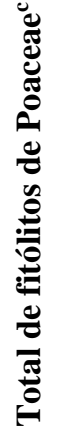 & 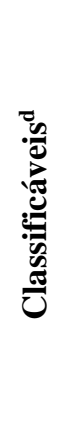 & 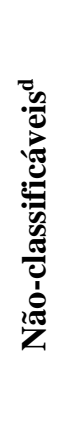 & $\stackrel{\circ}{\circ}$ & صَ & 里 \\
\hline S.A - 5 & 319 & 9 & 10 & 13 & 17 & 12 & 4 & 8 & 6 & 6 & 0 & 15 & 58 & 79 & 21 & 0,22 & 33 & 74 \\
\hline S.A - 10 & 317 & 14 & 12 & 13 & 16 & 11 & 4 & 7 & 4 & 5 & 0 & 15 & 60 & 77 & 23 & 0,21 & 43 & 76 \\
\hline S.A - 15 & 282 & 12 & 17 & 11 & 18 & 10 & 3 & 7 & 5 & 4 & 0 & 13 & 60 & 82 & 18 & 0,19 & 48 & 70 \\
\hline S.A - 20 & 271 & 12 & 14 & 9 & 16 & 12 & 4 & 6 & 3 & 6 & 0 & 18 & 63 & 80 & 20 & 0,15 & 43 & 90 \\
\hline S.A - 25 & 285 & 11 & 11 & 10 & 15 & 14 & 5 & 11 & 2 & 7 & 0 & 14 & 62 & 79 & 21 & 0,16 & 36 & 77 \\
\hline S.A - 30 & 302 & 12 & 9 & 8 & 15 & 14 & 5 & 9 & 6 & 7 & 0 & 15 & 62 & 81 & 20 & 0,13 & 33 & 75 \\
\hline S.A - 35 & 306 & 11 & 11 & 12 & 15 & 14 & 4 & 11 & 3 & 5 & 0 & 15 & 59 & 75 & 25 & 0,2 & 38 & 70 \\
\hline S.A- 40 & 286 & 12 & 9 & 8 & 13 & 9 & 4 & 17 & 10 & 6 & 0 & 11 & 70 & 83 & 18 & 0,12 & 30 & 46 \\
\hline S.A - 45 & 284 & 14 & 8 & 10 & 13 & 16 & 4 & 17 & 6 & 4 & 0 & 8 & 61 & 79 & 21 & 0,17 & 36 & 39 \\
\hline P.S A - 15 & 527 & 16 & 19 & 14 & 21 & 9 & 2 & 3 & 2 & 4 & 1 & 10 & 66 & 87 & 13 & 0,26 & 62 & 96 \\
\hline P.S O1 - 88 & 404 & 15 & 18 & 14 & 19 & 11 & 2 & 4 & 3 & 4 & 1 & 8 & 55 & 87 & 13 & 0,25 & 60 & 80 \\
\hline P.S O2 - 175 & 382 & 18 & 21 & 16 & 12 & 9 & 3 & 3 & 4 & 6 & 0 & 7 & 62 & 83 & 17 & 0,26 & 62 & 91 \\
\hline
\end{tabular}

Chueng, K. F., Coe, H. H. G., Fagundes, M., Vasconcelos, A. M. C., Ricardo, S. D. F. 
a- cm; b- unidades em três transectos horizontais; c- \% de fitólitos classificáveis; d- \% do total de fitólitos; e- D/P = globular granulatel (bulliform parallelepipedal + bulliform cuneiform + acicular + short cells $) ; \mathrm{f}-\mathrm{Bi}=[($ bulliform parallelepipedal + bulliform cuneiform) / (bulliform parallelepipedal + bulliform cuneiform + acicular + short cells $)] \mathrm{x}$ $100 ; \mathrm{g}-\mathrm{Ic}=[($ rondel + polylobate + trapeziform $) /($ rondel + polylobate + trapeziform + saddle + cross + bilobate $)] \mathrm{x} 100$

Os principais tipos de fitólitos observados também foram os de gramíneas (de 55 a 66\%), principalmente os bulliform (33 a 39\%), seguidos dos produzidos pelas palmeiras (12 a $21 \%)$ e pelas dicotiledôneas lenhosas (14 a 16\%). Entre os fitólitos produzidos nas células curtas (short-cells) das Poaceae e que permitem identificar as subfamílias, destacam-se os de ambientes temperados ou tropicais de altitude, como o rondel (7 a 10\%) e trapeziform (4 a 6\%) e os característicos de ambientes úmidos como bilobate
(3 a 4\%), cross $(2$ a $4 \%$ ) e polylobate (0 a $1 \%)$, indicando um ambiente semelhante ao atual. Como se pode observar na Tabela 2 e na Figura 8B, de uma maneira geral, a distribuição desses tipos foi bastante homogênea ao longo do perfil, podendo ser destacadas uma diminuição do globular echinate no horizonte $\mathrm{O} 2$ (de 21 para $12 \%$ ) e dos tipos que indicam ambientes úmidos (cross, bilobate e polylobate) no horizonte A (de $10 \%$ no horizonte $\mathrm{O} 2$ para $7 \%$ ).

Chueng, K. F., Coe, H. H. G., Fagundes, M., Vasconcelos, A. M. C., Ricardo, S. D. F. 


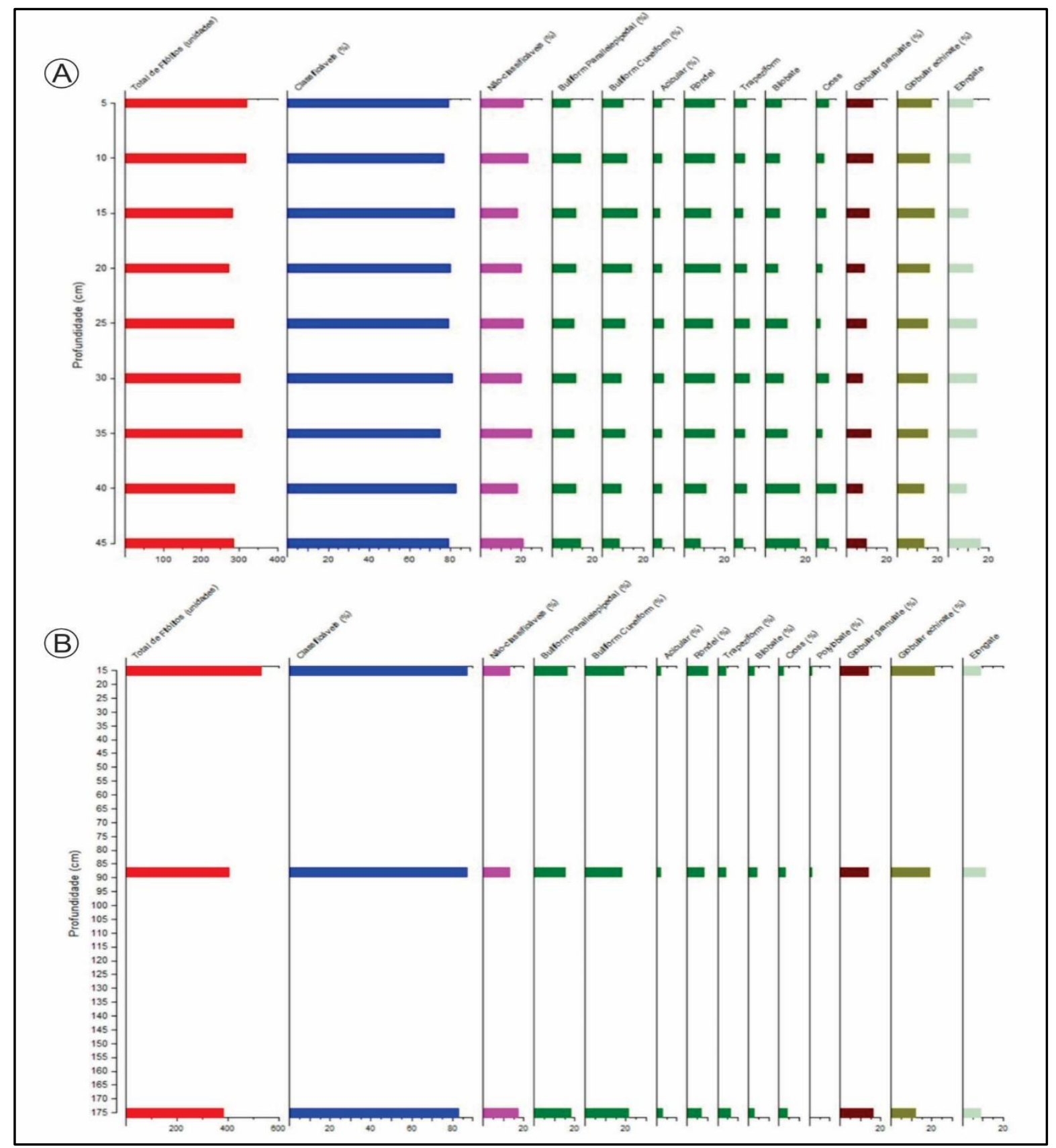

Figura 8: Resultados das análises fitolíticas: A) Sítio Arqueológico; B) Perfil de Organossolo

Chueng, K. F., Coe, H. H. G., Fagundes, M., Vasconcelos, A. M. C., Ricardo, S. D. F. 


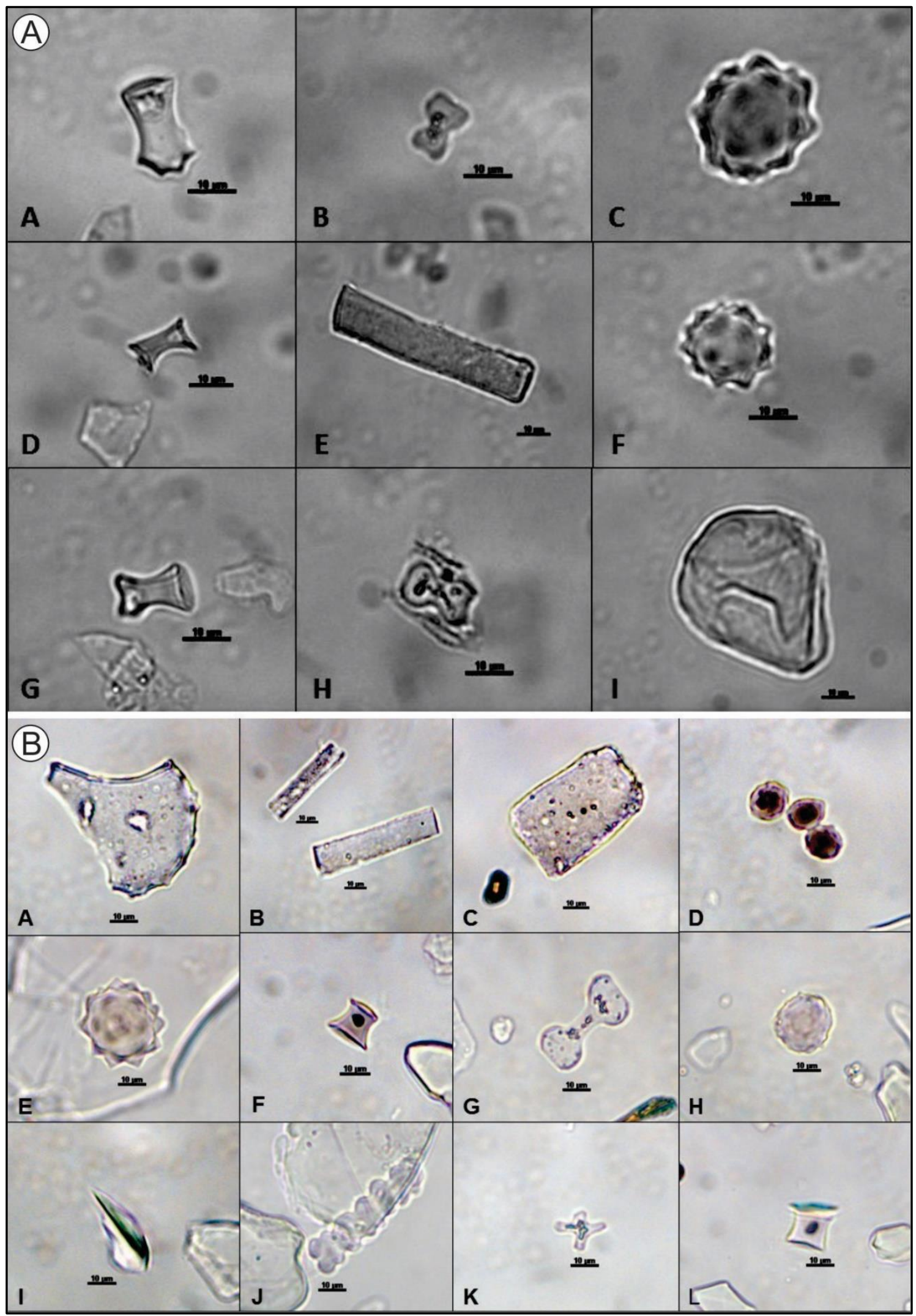

Figura 9: Fotografias ao microscópio ótico dos principais tipos de fitólitos observados: A: no Sítio Arqueológico: A, D e G) Rondel; B) Cross; C e F) Globular echinate; E) Elongate; H) Bilobate; I) Bulliform Cuneiform; B: no perfil de Organossolo: A) Bulliform cuneiform; B) Elongate; C-Bulliform

Chueng, K. F., Coe, H. H. G., Fagundes, M., Vasconcelos, A. M. C., Ricardo, S. D. F. 
parallelepipedal; D e H) Globular granulate; E) Globular echinate; F e L) Rondel; G) Bilobate; I) Acicular; J) Cross articulados; K) Cross (Fotos Chueng, 2016).

Os índices D/P (densidade arbórea), Bi (estresse hídrico) e Ic (climático) não variaram ao longo do perfil (Tabela 2). Os valores de índices $\mathrm{D} / \mathrm{P}$ baixos (entre $0,13 \mathrm{e}$ 0,22 no S.A e 0,25 a 0,26 no P.S) são similares aos encontrados por Augustin et al. (2014), Barros et al. (2016), Alexandre et al. (1999) para áreas de cerrado em Minas Gerais. Os valores do índice Bi variaram de baixos, no Sítio Arqueológico (de 30 a 48\%), a moderados (60 a 62\%), no Organossolo. Valores médios do índice Bi (48 a 77\%) foram encontrados por Augustin et al. (2014), na região de Morrinhos, MG, indicando um ambiente de estabilidade geomorfológica. Os índices Ic foram elevados (de 70 a 90\%) no Sítio Arqueológico, com exceção das 2 camadas mais profundas ( 39 a $46 \%$ ) e ainda maiores no Organossolo (80 a 96\%).

Os resultados sugerem que, na faixa cronológica de ocupação do sítio arqueológico, entre 7225 anos A.P. e 480 anos A.P. (Fagundes, 2016) a região era recoberta por uma vegetação predominantemente de campos rupestres (D/P baixo e Ic indicando predomínio de gramíneas adaptadas a temperaturas mais baixas devido à altitude), com estresse hídrico (índice $\mathrm{Bi}$ ) moderado durante todo o período estudado.

\section{Conclusão}

A reconstituição paleoambiental é um componente fundamental de qualquer projeto de pesquisa arqueológica. Como consequência de sua abundância, durabilidade e morfologias diagnósticas, os fitólitos têm sido cada vez mais usados para reconstruir aspectos de paleoambientes do Quaternário Tardio em vários tipos de sedimentos.

As análises fitolíticas das amostras do Sítio Arqueológico Cabeças 4 e do perfil de Organossolo próximo ao mesmo indicaram predomínio de tipos de fitólitos de Poaceae e Arecaceae. Além disso, os fitólitos se mostraram preservados, distribuídos de forma homogênea em profundidade e com índices que não variaram ao longo do perfil, sugerindo condições de estabilidade e de uma vegetação predominantemente de campos rupestres. A similaridade dos resultados das amostras coletadas em ambiente natural (perfil de solo) e no sítio arqueológico sugere que os fitólitos são bons indicadores do ambiente, mesmo em locais com interferência antrópica. Os resultados fitolíticos corroboram as pesquisas arqueológicas já desenvolvidas na área, que ressaltam esta região como propícia para as ocupações de grupos de caçadores coletores e horticultores.

Agradecimentos: Ao CNPq, pela concessão da bolsa de Doutorado e pelo auxílio à Pesquisa (Processo: 445209/2014-3) e ao LAEP-UFVJM.

\section{Referências}

Albert, R. M., Bamford, M. K., Esteban, I., 2015. Reconstruction of ancient palm vegetation landscapes using a phytolith approach. Quaternary International 369: 51-66.

Astudillo, F. J., 2018. Soil phytoliths as indicators of initial human impact on San Cristóbal Island, Galápagos. Palaeogeography, Palaeoclimatology, Palaeoecology 490: 522-532.

Augustin, C. H. R. R., Coe, H. H. G., Chueng, K. F., Gomes, J. G., 2014. Analysis of geomorphic dynamics in ancient quartzite landscape using phytolith and carbon isotopes, Espinhaço Mountain Range, Minas Gerais, Brazil. Géomorphologie 4: 355-376.

Babot, M. P., Musaubach, M. G., Plos, A., 2017. An archaeobotanical perspective in the study of inflorescence phytoliths of wild grasses from arid and semi-arid environments of Argentina. Quaternary International 434: 129-141.

Ball, T., Chandler-Ezell, K., Dickau, R., Duncan, N., Hart, T. C., Iriarte, J., Lentfer, C., Logan, A., Houyuan, L., Madella, M., Pearsall, D., Piperno, D. R., Rosen, A. M., Vrydaghs, L., Weisskopf, A., Zhang, J., 2016. Phytoliths as a tool for investigations of agricultural origins 
and dispersals around the world. Journal of Archaeological Science 68: 32-45.

Barros, L. F. P., Coe, H. H. G., Seixas, A. P., Magalhães, A. P., Macario, K. D., 2016. Paleobiogeoclimatic scenarios of the Late Quaternary inferred from fluvial deposits of the Quadrilátero Ferrífero (Southeastern Brazil). Journal of South American Earth Sciences 67: 71-88.

Calegari, M.R., Madella, M., Vidal-Torrado, P., Pessenda, L. C. R., Marques, F. A., 2013. Combining phytoliths and $£^{13} \mathrm{C}$ matter in Holocene palaeoenvironmental studies of tropical soils: An example of an Oxisol in Brazil. Quaternary International 287: 47-55.

Calegari, M. R., Madella, M., Buso, A. A., Osterrieth, M. L., Lorente, F. L., Pessenda, L. C. R., 2015. Inferências sobre Vegetação e Clima no Holoceno a partir de Fitólitos e Pólen da Lagoa do Macuco, Litoral Norte do Estado do Espírito Santo (Brasil). Quaternary and Environmental Geosciences 06 (1): 4150.

Calegari, M. R., Madella, M., Brustolin, L.T., Pessenda, L. C. R., Buso, A. A., Francisquini, M. I., Bendassolli, J. A., Vidal-Torrado, P., 2017. Potential of soil phytoliths, organic matter and carbon isotopes for small-scale differentiation of tropical rainforest vegetation: A pilot study from the campos nativos of the Atlantic Forest in Espírito Santo State (Brazil). Quaternary International 437: 156-164.

Calegari, M. R., Paisani, S. D. L., Cecchet, F. A., Ewald, P. I. L., Osterrieth, M. L., Paisani, J. C., Pontelli, M. E., 2017. Phytolith signature on the Araucarias Plateau - Vegetation change evidence in Late Quaternary (South Brazil). Quaternary International 434: 117-128.

Coe, H. H. G., Ramos, Y. B. M., Silva, A. L. C., Souza, L. O. F., Macário, K. D., Dias, R. R., 2018. Paleovegetação da Ilha Grande (Rio de Janeiro) no Holoceno através do estudo de fitólitos e isótopos do carbono. Revista Brasileira de Geografia Física 11 (02): 456-476.

Coe, H. H. G., Ricardo, S. D. F., Sousa, L.O.F., Dias, R. R., 2017. Caracterização de fitólitos de plantas e assembleias modernas de solo da caatinga como referência para reconstituições paleoambientais. Quaternary and Environmental Geosciences 8: 9-21.

Coe, H. H. G., Souza, R. C. C. L., Duarte, M. R., Ricardo, S. D. F., Machado, D. O. B. F., Macario, K. C. D., Silva, E. P., 2017. Characterisation of phytoliths from the stratigraphic layers of the Sambaqui da Tarioba (Rio das Ostras, RJ, Brazil). FLORA 236-237: 1-8.

Coe, H. H. G., Seixas, A. P., Gomes, J. G., Barros, L. F. P., 2015. Reconstituição Paleobiogeoclimática através de Fitólitos e Isótopos de Carbono no Quadrilátero Ferrífero, MG. Revista Equador 4: 14391447.

Coe, H. H. G., Macario, K., Gomes, J. G., Chueng, K. F., Oliveira, F., Gomes, P. R. S., Carvalho, C., Linares, R., Alves, E., Santos, G. M., 2014. Understanding Holocene variations in the vegetation of Sao Joao River basin, southeastern coast of Brazil, using phytolith and carbon isotopic analyses. Palaeogeography, Palaeoclimatology, Palaeoecology 415: 59-68.

Coe, H. H. G., Alexandre, A., Carvalho, C. N., Santos, G. M., Silva, A. S., Sousa, L. O. F., Lepsch, I. F., 2013. Changes in Holocene tree cover density in Cabo Frio (Rio de Janeiro, Brazil): Evidence from soil phytolith assemblages. Quaternary International 287: 63-72

Evett, R. R., Cuthrell, R. Q., 2016. A conceptual framework for a computerassisted, morphometric-based phytolith analysis and classification system. Journal of Archaeological Science 68: 70-78.

Fagundes, M., 2013. O Projeto Arqueológico Alto Jequitinhonha (PAAJ) e a Área Arqueológica de Serra Negra, Alto Araçuaí, Minas Gerais. Revista Espinhaço 2(2): 68-95.

Fagundes, M., 2016. O Projeto Arqueológico Alto Jequitinhonha - Sítios arqueológicos, Cultura material e Cronologias para compreensão das Ocupações Indígenas Holocênicas no 
Alto Vale do Rio Araçuaí, Minas Gerais -Brasil. Vozes dos Vales 10: 01-25.

Fagundes, M. Baggio Filho, H., Silva, A. C., Greco, W. S., D’ávila, M. A., Galvão, L. G., 2017. O Sítio Arqueológico Sampaio, Alto Vale do Araçuaí, Felício Dos Santos, Minas Gerais: Paisagem, Cronologia e Repertório Cultural para Compreensão das Ocupações Humanas Antigas do Espinhaço Meridional. Revista Espinhaço 01(11): 65-76.

Field, J. H., Kealhofer, L., Cosgrove, R., Coster, A. C. F., 2016. Humanenvironment dynamics during the Holocene in the Australian Wet Tropics of NE Queensland: A starch and phytolith study. Journal of Anthropological Archaeology 44: 216-234.

Fonseca, B. M., Augustin, C. H. R. R., 2014. Análise morfométrica de bacias de drenagem e sua relação com a estrutura geológica, serra do Espinhaço Meridional-MG. Revista Brasileira de Geomorfologia 15 (2), 153-172.

Hart, T. C., 2016. Issues and directions in phytolith analysis. Journal of Archaeological Science 68: 24-31.

Hodson, J. M., 2016. The development of phytoliths in plants and its influence on their chemistry and isotopic composition. Implications for palaeoecology and archaeology. Journal of Archaeological Science 68: 62-69.

Hyland, E.; Smith, S. Y.; Sheldon, N. D., 2013. Representational bias in phytoliths from modern soils of central North America: Implications for paleovegetation reconstructions. Palaeogeography, Palaeoclimatology, Palaeoecology 374: 338-348.

Ishida, S., Parker, A. G., Kennet, D., Hodson, M. J., 2003. Phytolith analysis from the archaeological site of Kush, Ras al-Khaimah, United Arab Emirates. Quaternary Research 59 59, 310-321.

Isnardis, A., 2013. Pedras na Areia. As Indústrias Líticas e o Contexto Horticultor do Holoceno Superior na Região de Diamantina, Minas Gerais. Revista Espinhaço 2(2): 54-67.

Luz, L. D.; Kalinovski, C. Z.; Parolin, M.; Filho, E. E. S., 2015. Estágio Atual do
Conhecimento sobre Fitólitos no Brasil. Terræ Didatica 11(1):52-64.

McCune, J. L., Vellend, M., Pellatt, M.G., 2015. Combining phytolith analysis with historical ecology toreveal the long-term, local-scale dynamics within a savannahforest landscape mosaic. Biodivers. Conserv. 24: 609-626

Neumann, K., Fahmy, A. G., MüllerScheebel, N., Schmidt, M., 2017. Taxonomic, ecological and paleoecological significance of leaf phytoliths in West African grasses. Quaternary International 434: 15-32.

Paisani, S. D. L., Paisani, J. C., Osterrieth, M. L., Pontelli, M. E., 2016. Significado Paleoambiental de Fitólitos em Registro Pedoestratigráfico de Paleocabeceira de Drenagem - Superfície de Palmas - Água Doce (Sul do Brasil). São Paulo, UNESP, Geociências 35 (3): 429-445.

Parolin, M., Monteiro, M. R., Coe, H. H. G., Colavite, A. P., 2017. Considerações Paleoambientais do Holoceno Médio por Meio de Fitólitos na Serra do Cadeado, Paraná. Revista do departamento de geografia (USP), SBGFA: 96-103.

Pearsall, D. M., 2016. The Phytoliths in the Flora of Ecuador project: Perspectives on phytolith classification, identification and establishing regional phytolith databases. Journal of Archaeological Science 68: 89-97.

Power, R. C., Rosen, A. M., Nadel, D., 2014. The economic and ritual utilization of plants at the Raqefet Cave Natufian site: The evidence from phytoliths. Journal of Anthropological Archaeology 33: 49-65.

Santos, C. P., Coe, H. H. G., Ramos, Y. B. M., Sousa, L.O.F., Silva, A. L. C., Freire, D. G., Silvestre, C. P., 2017. Caracterização das comunidades vegetais na Restinga de Maricá, Rio de Janeiro, Sudeste do Brasil. Revista Tamoios 1: 121-135.

Santos, C. P., Coe, H. H. G., Borrelli, N. L., Silva, A. L. C., Sousa, L.O.F., Ramos, Y. B. M., Silvestre, C. P., Seixas, A. P., 2015. Opal phytolith and isotopic studies of 'Restinga' communities of Maricá, Brazil, as a modern reference for paleobiogeoclimatic reconstruction.

Chueng, K. F., Coe, H. H. G., Fagundes, M., Vasconcelos, A. M. C., Ricardo, S. D. F. 
Brazilian Journal of Oceanography 63: 255-270.

Silva, L. A., 2017. Cadeia operatória do conjunto artefatual lítico do Holoceno médio: abrigo Cabeças 4, Felício dos Santos, Alto Vale do Araçuaí, MG. Dissertação de Mestrado. Universidade Federal de Pelotas, PPG-Antropologia, Pelotas-RS, 100p.

Silva, D. W., Filho, M. C., Parolin, M.; Bertolli, L. G., 2016. Análise paleoambiental a partir dos principais morfotipos de fitólitos encontrados em sedimento turfoso na região de Guarapuava-Paraná. Ambiência Guarapuava (PR) 12 (1): 13 -32.

Shillito, L-M., 2013. Grains of truth or transparent blindfolds? A review of current debates in archaeological phytolith analysis. Veg. Hist. Archaeobot 22: 71-82.
Vrydaghs, L., Ball, T. B., Devos, Y., 2015. Beyond redundancy and multiplicity. Integrating phytolith analysis and micromorphology to the study of Brussels Dark Earth. Journal of Archaeological Science 68: 79-88.

Yost, C. L., Jackson, L. J., Stone, J. R.; Cohen, A. S., 2018. Subdecadal phytolith and charcoal records from Lake Malawi, East Africa imply minimal effects on human evolution from the $\sim 74 \mathrm{ka}$ Toba supereruption. Journal of Human Evolution 116: 75-94

Watling, J., Iriarte, J., 2013. Phytoliths from the coastal savannas of French Guiana. Quaternary International 287: 162-180.

Zurro, D., Granero, J. J. G., Lancelloti, C., Madella, M., 2016. Directions in current and future phytolith research. Journal of Archaeological Science 68: 112-117.

Chueng, K. F., Coe, H. H. G., Fagundes, M., Vasconcelos, A. M. C., Ricardo, S. D. F. 